Bio - grafia. Escritos sobre la Biología y su Enseñanza. ISSN 2027

Edición Extraordinaria. p.p. 1575-1589

Memorias del VIII Encuentro Nacional de Experiencias en Enseñanza de la Biología y la Educación Ambiental. III Congreso Nacional de Investigación en Enseñanza de la Biología.

\title{
Parodia musical como recurso educativo para estudiar conceptos ambientales
}

Melo, Tafarel Fernandes Tavares de ; Dias, Márcia Adelino da Silva ${ }^{2}$

Resumen: La práctica de asociar a la musica sus factores sociales se refleja en el aprendizaje en diferentes niveles y ambientes, por lo que es una característica potencialmente constructivo. En este trabajo tomamos la parodia como un elemento para estudiar cómo la música contribuye al desarrollo de la conciencia mediante la investigación de los conceptos ambientales expresadas por los estudiantes de Ensino Médio (Escuela Secundaria). Por lo tanto, al final de un curso corto realizado en una escuela pública en Campina Grande - PB (Brasil), fueron construidos parodias por estudiantes que recibieron tratamiento de los datos cualitativos, como se propone en la "análisis temática" (Bardin, 2011). Los elementos que surgieron del análisis contribuyeron al conocimiento de los conceptos expresados por los participantes en relación con el medio ambiente, las relaciones sociales y el proyecto de jardín escolar desarrollado en el campo de estudio, clasificados en identificación, conceptos ambientales amplios y conceptos ambientales estrictos. Señaló la importancia de la parodia como recurso estimulante a la construcción de conciencia crítica, haciendolo un gran articulador para la comprensión de diversos conocimientos circunscritos dentro de las Ciencias Naturales.

Palabras clave: Educación Ambiental, Enseñanza y Aprendizaje, Herramienta de Enseñanza.

1 Universidade Estadual da Paraíba - Brasil; e-mail: tafarel.melo@gmail.com

2 Universidade Estadual da Paraíba - Brasil; e-mail: adelinomarcia@yahoo.com.br 1575 
Bio - grafia. Escritos sobre la Biología y su Enseñanza. ISSN 2027

Edición Extraordinaria. p.p. 1575-1589

Memorias del VIII Encuentro Nacional de Experiencias en Enseñanza de la Biología y la Educación Ambiental. III Congreso Nacional de Investigación en Enseñanza de la Biología.

\title{
Musical parody as an educational resource to study environmental concepts
}

\begin{abstract}
The practice of associating music social factors reflected in learning at different levels and environments, making it a potentially constructive feature. In this paper we take the parody as an element to study how music contributes to the development of awareness through research of environmental concepts expressed by students of high school. Therefore, at the end of a short course held in a public school in Campina Grande - PB (Brazil), were built by the students parodies who received treatment of qualitative data, as proposed "thematic analysis" (Bardin, 2011). The elements that emerged from the analysis contributed to the knowledge of the concepts expressed by participants in relation to the environment, social relationships and the school garden project developed in the field of study, categorized into identification, broad environmental concepts and strict environmental concepts. Signaled the importance of parody as a stimulant use of building critical consciousness, making it a great articulator for understanding various knowledge circumscribed within the Natural Sciences.
\end{abstract}

Key words: Environmental Education, teaching-learning, teaching tool.

\section{Introdução}

A educação, especificamente no contexto brasileiro, historicamente tem sido marcada por problemas diversos, dentre os quais destacamos a desvalorização do profissional docente, extenso déficit estrutural e de pessoal técnico-administrativo e uma prática de ensino defasada e retrógrada, sobretudo, ancorada no "bancarismo" no sentido a que se refere Paulo Freire. Apesar da legislação educacional, que evoluiu consideravelmente desde a primeira LDB, a escola brasileira - com raras exceções - ainda não cumpre com excelência muitos pontos existentes nessas leis.

Os PCNEM (2000) enfatizam claramente: a formação geral, em oposição à formação 
Bio - grafia. Escritos sobre la Biología y su Enseñanza. ISSN 2027

Edición Extraordinaria. p.p. 1575-1589

Memorias del VIII Encuentro Nacional de Experiencias en Enseñanza de la Biología y la Educación Ambiental. III Congreso Nacional de Investigación en Enseñanza de la Biología.

específica; o desenvolvimento de capacidades de pesquisar, buscar informações, analisá-las e selecioná-las; a capacidade de aprender, criar, formular, ao invés do simples exercício de memorização. A última LDB - 9394/1996 destaca "o aprimoramento do educando como pessoa humana, incluindo a formação ética $e$ o desenvolvimento da autonomia intelectual $e$ do pensamento crítico" (Brasil, 1996; Art. 35, III) como pontos importantes a serem construídos durante esse nível educacional.

Entretanto, a maioria dos estudantes que concluem o nível médio possuem muitos problemas ligados à racionalização ou à capacidade de posicionar-se criticamente diante de situações cotidianas. Muitos desses jovens concluintes do referido nível de escolarização se deparam com a impossibilidade de acesso ao Ensino Superior, ou mesmo sequer o almejam devido à falta de perspectivas, em grande medida, consequentes do modelo de educação vigente.

0 contexto educacional brasileiro ancora-se, quase que hegemonicamente, no ensino "tradicional", materializado historicamente, tendo maior visibilidade a partir do século XIX. A LDB vigente enfatiza a necessidade de inovar na prática pedagógica e estimular os discentes, ao afirmar que o Ensino Médio (EM) deve adotar "metodologias de ensino e de avaliação que estimulem a iniciativa dos estudantes" (Brasil, 1996, Art. 36, II).

Para Santos (2005), as inovações educacionais e pedagógicas vêm sendo discutidas com o objetivo coletivo de esclarecer o seu significado e propor melhorias na escola. Hernandez \& Sancho (2000) lembra que um sistema educacional inovador é aquele em que existem canais de comunicação entre o planejador e os que realizam a inovação. Assim, todos os grupos relacionados com a inovação estão vinculados a ela, seu sentido é claro para todos os grupos envolvidos e os conflitos são interpretados como sinônimo de que a inovação é necessária.

Em contradição com o que é frequentemente observado na prática escolar, as perspectivas norteadoras do EM, implementadas pelo Governo Federal incentivam o uso de diversificadas estratégias e metodologias de ensino com o objetivo de modificar o padrão existente. Os PCNEM propõem uma perspectiva de ensino voltada para a produção de conhecimento efetivo, de significado próprio, não somente propedêutico, pautando-se pela interdisciplinaridade e contextualização, imprimindo assim, um sentido de ensino de caráter amplo, de forma que os aspectos e conteúdos tecnológicos associados ao aprendizado científico e matemático sejam parte essencial da formação cidadã de caráter universal e não somente profissionalizante.

Na direção do atendimento a essas perspectivas, o Programa Ensino Médio Inovador surge 
Bio - grafia. Escritos sobre la Biología y su Enseñanza. ISSN 2027

Edición Extraordinaria. p.p. 1575-1589

Memorias del VIII Encuentro Nacional de Experiencias en Enseñanza de la Biología y la Educación Ambiental. III Congreso Nacional de Investigación en Enseñanza de la Biología.

no cenário educacional brasileiro integrando ações do Plano de Desenvolvimento da Educação (PDE), como estratégia do Governo Federal para mudanças significativas nos currículos do EM. A partir de seus direcionamentos, são fomentadas propostas curriculares inovadoras nas escolas, contando com apoio técnico e financeiro, consoante à disseminação da cultura de um currículo dinâmico, flexível e compatível com as exigências da sociedade contemporânea.

Uma outra estratégia que vem se somar ao PDE na perspectiva de inovação e reconstrução do modelo educacional brasileiro, é o Programa de Bolsas de Iniciação à Docência (PIBID), que tem possibilitado a formação de educadores com visão inovadora de ensino. O programa busca inserir os licenciandos no cotidiano de escolas públicas, proporcionando-lhes oportunidades de criar e participar de experiências metodológicas, tecnológicas e práticas docentes de caráter inovador e interdisciplinar que busquem contribuir com a minimização dos problemas identificados nos processos de ensino-aprendizagem. Assim, diversas ferramentas vêm sendo desenvolvidas e utilizadas no âmbito das escolas públicas.

Dentre as várias ferramentas metodológicas que vem sendo aplicadas em sala de aula, a música apresenta-se como uma indispensável estratégia, de caráter lúdico, no processo de ensino/aprendizagem. Segundo Loureiro (2003), a música vem desempenhando, ao longo da história, um importante papel no desenvolvimento do ser humano, seja no aspecto religioso, moral ou social, contribuindo para a formação de valores indispensáveis ao exercício da cidadania. Campos (2008), afirma que o lúdico pode ser utilizado como promotor da aprendizagem nas práticas escolares, possibilitando a aproximação dos alunos ao conhecimento científico.

De acordo com as afirmações de Ferreira (2008), ao longo da existência do ser humano, a prática de associar qualquer disciplina à música sempre foi bastante utilizada e demonstrou muitas potencialidades como fator auxiliar no aprendizado, podendo ainda despertar $e$ desenvolver nos alunos sensibilidades mais aguçadas na observação de questões próprias à disciplina alvo, além de melhorar a qualidade do ensino e aprendizado, uma vez que estimula e motiva professores e alunos.

Conforme destaca também Granja (2006), a música é utilizada, em conjunto com atividades lúdicas, geralmente com as crianças do Ensino Fundamental e à medida que o estudante avança na escola esta vai perdendo a utilidade no ensino. Assim sendo, poucas são as experiências utilizando esta ferramenta no EM, apesar do seu caráter auxiliador no desenvolvimento do individuo como cidadão, na compreensão de conteúdos didáticos e na 
Bio - grafia. Escritos sobre la Biología y su Enseñanza. ISSN 2027

Edición Extraordinaria. p.p. 1575-1589

Memorias del VIII Encuentro Nacional de Experiencias en Enseñanza de la Biología y la Educación Ambiental. III Congreso Nacional de Investigación en Enseñanza de la Biología.

aproximação de professores e alunos. Muitas vezes a escola oferece disciplinas de música, entretanto, isoladamente, deixando de ser uma ferramenta disponível para outras disciplinas.

\section{Ensino de Ciências, Educação Ambiental e Construção do conhecimento}

Para Jacobi (2003), a reflexão sobre as práticas sociais, em um contexto marcado pela degradação permanente do meio ambiente e dos ecossistemas, envolve uma necessária articulação, imprimindo, consequentemente, sentido às ações em Educação Ambiental (EA). Paralelamente, Leff (2001) discorre sobre a impossibilidade de resolver os crescentes e complexos problemas ambientais e reverter suas causas sem que aconteça uma mudança radical nos sistemas de conhecimento, dos valores e dos comportamentos gerados pela dinâmica racional existente, fundamentada no aspecto econômico do desenvolvimento.

Trabalhar EA no âmbito escolar inserindo métodos inovadores nas atividades de sensibilização e conscientização pode contribuir para uma melhoria da qualidade de ensino $e$ para a preservação do ambiente escolar e da complexidade socioambiental em geral. Santos (2010), afirma que a EA deve compreender conceitos e técnicas culturalmente abrangentes, para que o cidadão possa ter a capacidade de identificar causas e efeitos dos problemas ambientais.

Segundo Barbosa e Batista (2011), o incentivo à capacidade criativa dos educandos estimula-os a serem mais autônomos e abertos a novas experiências intelectuais. Entretanto, "apesar do apelo social, a criatividade tem tido pouca atenção na prática educacional e também nas pesquisas nacionais em educação científica" (Barbosa \& Batista, 2011, p.04).

Neste contexto a EA deve fazer-se enquanto proposta inovadora, atendendo as necessidades dessa nova maneira de compreender o mundo, oportunizando situações nas quais possam ser desenvolvidas competências e habilidades caracterizadas por uma compreensão crítica do mesmo.

Trabalhos têm sido desenvolvidos envolvendo uma associação direta entre construtivismo e EA (Morgado, 2006; Muggler, 2004), em que são realizadas "oficinas culinárias" (Morgado, p.19), trabalhando de forma interdisciplinar "partindo da realidade (...), o que torna esta 
Bio - grafia. Escritos sobre la Biología y su Enseñanza. ISSN 2027

Edición Extraordinaria. p.p. 1575-1589

Memorias del VIII Encuentro Nacional de Experiencias en Enseñanza de la Biología y la Educación Ambiental. III Congreso Nacional de Investigación en Enseñanza de la Biología.

construção fácil, divertida e com certeza significativa" (Muggler, 2004).

Segundo Sousa (2012), as atividades lúdicas, considerando o ensino de ciências, atuam diretamente na educação dos discentes, transformando e inovando os processos de ensinoaprendizagem, sendo um instrumento de informação, observação e correlação entre os conhecimentos adquiridos em sala de aula e o cotidiano do aluno. Assim, por aliar os aspectos lúdicos aos cognitivos, entendemos que qualquer atividade recreativa é uma importante estratégia para o ensino e a aprendizagem de conceitos abstratos e complexos, favorecendo a motivação interna, o raciocínio, a argumentação, a interação entre alunos e entre professores e alunos.

Os alunos se configuram como sujeitos estéticos que, aliados à cultura popular, são capazes de proporcionar a construção de seus conhecimentos, permitindo que sejam valorizados: sua cultura, sua comunidade e, principalmente, a si próprios. (Damasceno, 2009).

\section{Metodologia}

A produção escrita elaborada pelos participantes foi objeto de análise, seguindo um procedimento de identificação de elementos fundamentais à construção de categorias. Tal processo consistiu no agrupamento de frases, fundamental à categorização, utilizando-se do método de "análise temática", proposto por Bardin (2011), mediante o uso dos léxicos encontrados nas produções. Foram recortados trechos específicos, contendo significações de ordem semântica, a fim de identificar a expressão de características dispostas em categorias.

Partindo do referencial metodológico de Bardin (2011), realizamos a análise em três etapas sequenciais: 1) pré-análise, caracterizada pela transcrição dos textos para a matriz no Excel 2010; 2) exploração, mediante organização em duas colunas, baseada na forma como os dados seriam posteriormente trabalhados, separando termos mediante características semânticas coesivas $e$, isoladamente, palavra por palavra, seguido à construção das categorias em função de presença/ausência, frequência e intensidade dos léxicos (Bardin, 2011), realizada com auxílio do software Modalisa 4.5; e 3) tratamento, constituído da construção das inferências com a interpretação dos dados explorados anteriormente 
Bio - grafia. Escritos sobre la Biología y su Enseñanza. ISSN 2027

Edición Extraordinaria. p.p. 1575-1589

Memorias del VIII Encuentro Nacional de Experiencias en Enseñanza de la Biología y la Educación Ambiental. III Congreso Nacional de Investigación en Enseñanza de la Biología.

(Quadro 1).

Quadro 1 - Esquema de análise utilizado nos processos de exploração e tratamento dos dados.

\begin{tabular}{lll}
\hline CATEGORIAS DE ANÁLISE & EXEMPLOS & CATEGORIAS \\
\hline Identificação com o projeto & "minha horta" & Identificação \\
Interesse & "eu quero ajudar" & \\
Compromisso & "a enxada me chamou" & $\begin{array}{l}\text { Concepção socioambiental } \\
\text { ampla }\end{array}$ \\
Companheirismo & "com Rosângela" & Concepção socioambiental \\
Reducionismo & "tu vai cavar" & restrita \\
Visão utilitarista de ambiente & "vou comer" & \\
\hline
\end{tabular}

A presença/ausência de léxicos determina a construção das categorias destacadas no quadro 1, enfatizando as concepções existentes no interior dos discursos (Bardin, 2011). A existência de pronomes possessivos em primeira pessoa, por exemplo, remete à proximidade existente entre o sujeito e o objeto do período textual analisado, neste caso uma identificação com o projeto, caracterizada pela categoria identificação (Quadro 1).

\section{Resultados e Discussões}

Ricklefs (2010) afirma que a atual condição de desenvolvimento da população humana interfere diretamente na biosfera, uma vez que os diversos ecossistemas estão integrados numa grande rede complexa. Por conseguinte, conforme tem sido relatado em diversos trabalhos (Fernandes, et. al, 2004; Severo, 2012), a forma como os indivíduos percebem o ambiente contribui significativamente para a sua ação no ambiente. Para Fernandes (2004), a percepção pode ser definida como uma tomada de consciência do ambiente pelo ser humano, ou seja, o ato de perceber o ambiente em que se está inserido, aprendendo a 
Bio - grafia. Escritos sobre la Biología y su Enseñanza. ISSN 2027

Edición Extraordinaria. p.p. 1575-1589

Memorias del VIII Encuentro Nacional de Experiencias en Enseñanza de la Biología y la Educación Ambiental. III Congreso Nacional de Investigación en Enseñanza de la Biología.

proteger e a cuidar dele, de modo que cada indivíduo percebe, reage e responde diferentemente às ações sobre o ambiente em que vive. Assim, cada resposta ou manifestação decorrentes deste quadro são resultado das concepções (individuais e/ou coletivas), dos processos cognitivos, julgamentos e expectativas de cada pessoa.

Os textos analisados neste trabalho apresentaram diversas afirmativas relacionadas às palavras-chave propostas para discussão, e boa parte dessas palavras está diretamente ligada à concepção dos participantes com relação ao meio ambiente, às relações sociais ou ao projeto da horta escolar desenvolvido no campo de estudo.

Conforme esperado, as produções textuais refletiram as concepções dos estudantes em relação ao projeto do qual fizeram parte durante um determinado período do ano. Muitas afirmações destacam, em primeiro plano, a identificação entre os estudantes participantes e o projeto desenvolvido, demonstrando assim, a visão positiva dos estudantes em relação à horta escolar (Quadro 2).

Quadro 2 - Classes de palavras observadas nos textos analisados, intensidade (verbos), exemplos e respectivas frequências.

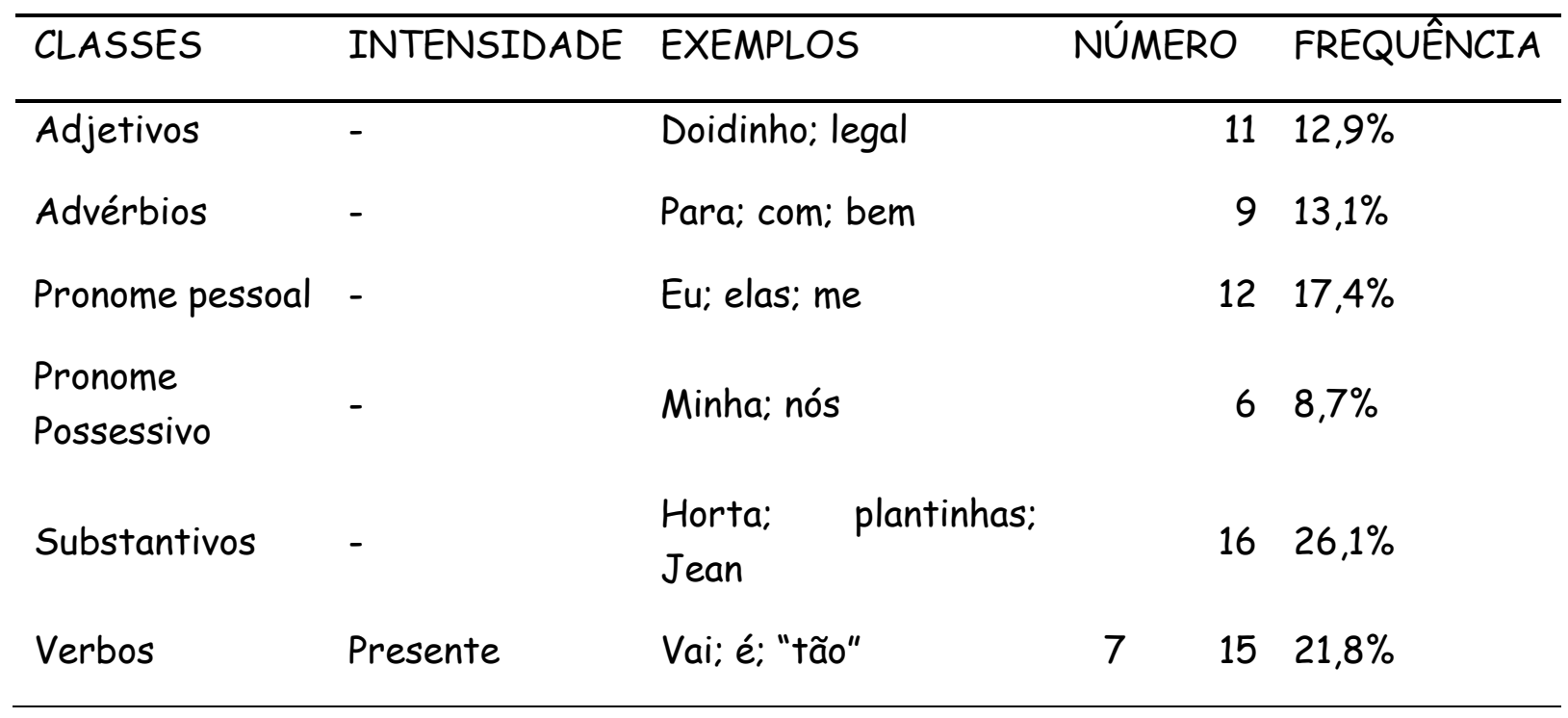


Bio - grafia. Escritos sobre la Biología y su Enseñanza. ISSN 2027

Edición Extraordinaria. p.p. 1575-1589

Memorias del VIII Encuentro Nacional de Experiencias en Enseñanza de la Biología y la Educación Ambiental. III Congreso Nacional de Investigación en Enseñanza de la Biología.

\begin{tabular}{lllll}
\hline Passado & Chamou; perguntei & 4 & \\
Infinitivo & Ajudar; pegar; limpar & 4 & & \\
& & TOTAL & 69 & $100 \%$ \\
\cline { 3 - 4 } & & &
\end{tabular}

De acordo com Bardin (2011), o estudo do léxico permite um balanceamento das informações disponibilizadas mediante o conteúdo, determinando ênfases/ausências e suas respectivas significações. Pode-se destacar a presença de pronomes pessoais em primeira pessoa indicando relação de proximidade, da mesma forma que a incidência de pronomes possessivos em primeira pessoa reflete a relação de posse direta. Assim, no período minha horta é bem legal, por exemplo, há uma relação de posse, representada pela união entre o pronome minha e o substantivo horta, um conector positivo, representado pelo verbo é, e dois termos avaliativos, ambos positivos, o advérbio bem e o adjetivo legal.

Os trechos vertem por três categorias, mediante sua própria semântica, observando-se uma maior incidência de afirmações que refletem identificação com o projeto. Alguns elementos podem ser classificados paralelamente em duas categorias, como em vamos ajudar! que, por exemplo, reflete identificação com o projeto, mediante o uso do verbo em $1^{a}$ pessoa, mas também pode indicar companheirismo, uma vez que este mesmo verbo está no plural (que indica proximidade), ou ainda compromisso, através da articulação semântica existente entre vamos e ajudar, que resulta em uma ação imperativa, que deve ter início rápido (Quadro 3).

Quadro 3 - Significações observadas nos textos das paródias mediante análise lexical. Classificação em categorias, com seus respectivos componentes e exemplos.

SIGNIFICAÇÕES OBSERVADAS

\begin{tabular}{lll}
\hline CATEGORIAS COMPONENTES EXEMPLOS & INCIDENCIA
\end{tabular}


Bio - grafia. Escritos sobre la Biología y su Enseñanza. ISSN 2027

Edición Extraordinaria. p.p. 1575-1589

Memorias del VIII Encuentro Nacional de Experiencias en Enseñanza de la Biología y la Educación Ambiental. III Congreso Nacional de Investigación en Enseñanza de la Biología.

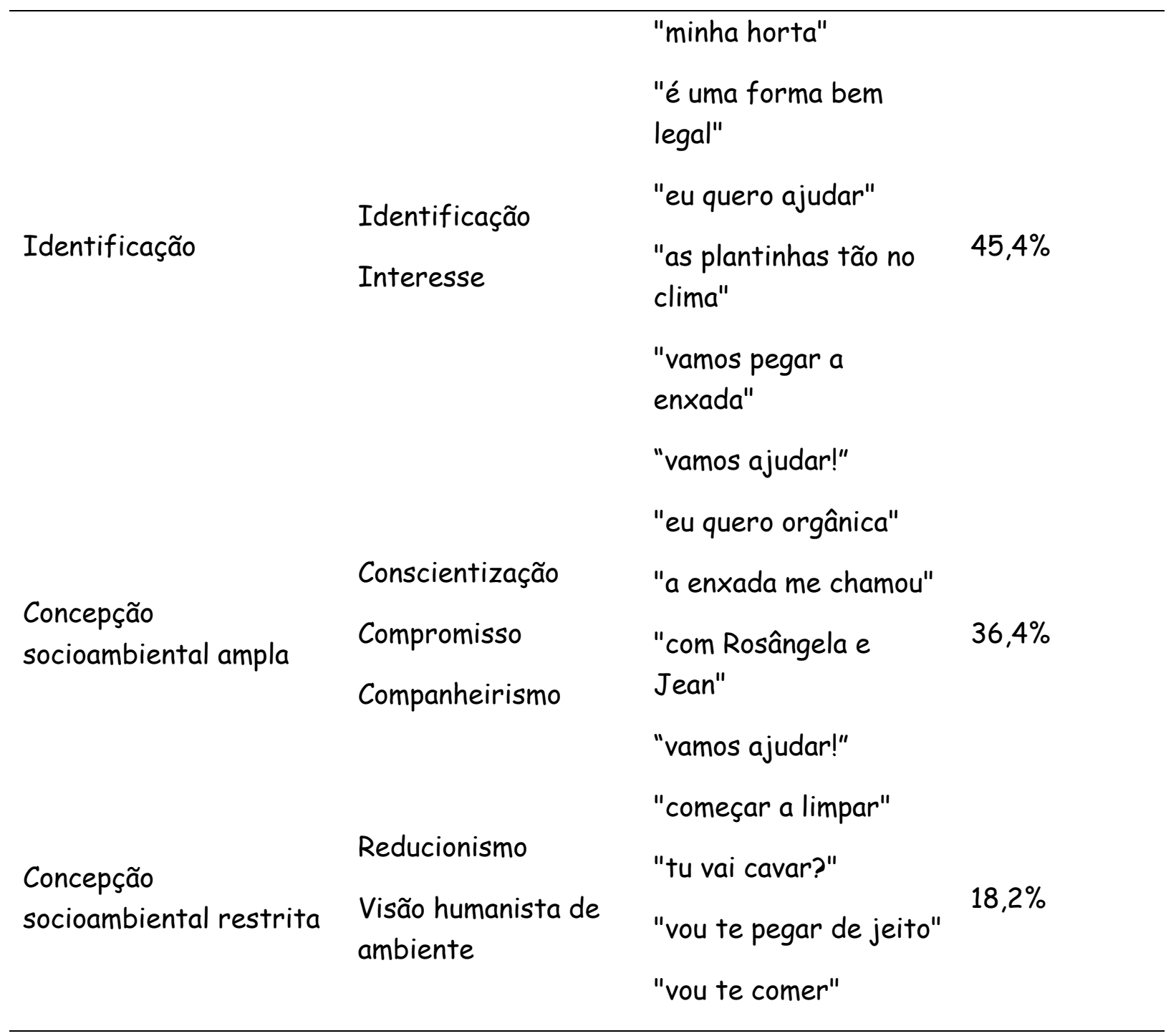

TOTAL $100 \%$

Ao analisarmos as paródias, muitas expressões, frases ou mesmo períodos remetem às concepções acima mencionadas. Há uma grande incidência de afirmativas que indicam uma conscientização com relação à prática orgânica da agricultura e ao meio ambiente, um 
Bio - grafia. Escritos sobre la Biología y su Enseñanza. ISSN 2027

Edición Extraordinaria. p.p. 1575-1589

Memorias del VIII Encuentro Nacional de Experiencias en Enseñanza de la Biología y la Educación Ambiental. III Congreso Nacional de Investigación en Enseñanza de la Biología.

compromisso com a natureza e a manutenção da horta, assim como algumas afirmações que demonstram a percepção de que o uso sustentável dos recursos, bem como o cuidado com eles, devem ser realizados não apenas individualmente, mas também em grupo, sob uma perspectiva de companheirismo. Alguns trechos das paródias foram destacados, contendo significações que correspondem a uma visão restrita do trabalho com a horta, isolando-o do contexto externo à escola ou restringindo-o ao seu aspecto produtivo, bem como a um posicionamento de superioridade em relação ao ambiente (18,2\%; Quadro 3).

O maior grupo de unidades de significação observado foi relacionado à identificação com o projeto, com 45,4\% dos dados (Quadro 3). A existência desta categoria - identificação -, associada ao alto número de exemplos existentes nela, indica uma ampla aceitação da proposta do projeto de horta escolar implementado na escola, ao qual foi articulado o desenvolvimento do minicurso. Diversas afirmações exprimem uma identificação com o trabalho em questão (minha horta ou eu quero horta, por exemplo), enquanto outras estão relacionadas ao interesse em trabalhar no ambiente da horta (doidinha para plantar ou eu quero ajudar, por exemplo).

Paralelamente, conscientização e compromisso são identificados em alguns trechos específicos das composições, como em: eu quero orgânica e a enxada me chamou. Nesses exemplos observa-se entre o discurso dos participantes uma concepção mais dinâmica da inserção do ser humano no meio ambiente, enfatizada pelo aspecto de interação $e$ subordinação do ser humano.

Outro aspecto importante a ser destacado reside em uma das categorias, a de percepção socioambiental ampla. Um dos trechos destacados das composições realizadas pelos estudantes apresenta citações diretas a si e a seus colegas, do que se infere demonstrar a compreensão de que o cuidado com o meio ambiente deve acontecer em grupo e está atrelado a uma boa relação com a sociedade.

A presença de concepção socioambiental restrita fica destacada em afirmações como vou te pegar de jeito ou vou te comer. Nesses casos, o estudante explicita um posicionamento utilitarista com relação ao conceito de ambiente, marcado pela subordinação do mesmo a ele. 
Bio - grafia. Escritos sobre la Biología y su Enseñanza. ISSN 2027

Edición Extraordinaria. p.p. 1575-1589

Memorias del VIII Encuentro Nacional de Experiencias en Enseñanza de la Biología y la Educación Ambiental. III Congreso Nacional de Investigación en Enseñanza de la Biología.

\section{Conclusões}

Conforme o exposto, sinalizamos a relevância da paródia como recurso ao estudo de conceitos importantes para a consciência critica, neste caso, à horta escolar e suas respectivas implicações no cotidiano dos estudantes, o que faz dela um articulador para a compreensão de conhecimentos diversos circunscritos no âmbito das Ciências Naturais.

Apesar de alguns trechos evidenciarem uma visão utilitarista de meio ambiente, de maneira geral, a análise dos resultados indica que houve, entre os estudantes participantes, uma considerável conscientização em relação aos temas abordados durante o minicurso. Entre os discursos analisados, observou-se a compreensão de conceitos existentes em EA, abordados durante o evento, a exemplos de uso sustentável de recursos naturais, desigualdades sociais e saúde.

Percebe-se claramente em diversos trechos das paródias analisadas uma identificação com - ambiente de estudos representado pela horta, ambiente escolar $e$, consequentemente, com os demais participantes do projeto. Do mesmo modo, é evidente a concepção dos estudantes em relação à importância do trabalho, bem como da participação deles no projeto.

A ludicidade da paródia proporciona uma aproximação entre conteúdos abordados e os alunos, contribuindo para a melhoria da aprendizagem de conceitos significativos para a formação da consciência crítica. Assim, pode-se afirmar que a paródia contribui de forma satisfatória como metodologia para o processo de ensino-aprendizagem em $E A$, uma vez que possibilita uma facilitação na construção de estruturas mentais nos discentes.

Um dos aspectos que merecem destaque ao analisarmos tal perspectiva de trabalho reside no caráter avaliativo inserido no uso da paródia quando trabalhada segundo a proposta descrita. Ela permite aos professores obter um feedback em relação à aprendizagem dos estudantes e, assim, identificar concepções e o nivel de aprendizagem dos alunos. Destarte, a paródia pode atuar também na composição de uma avaliação continuada, não apenas em $E A$, mas também em qualquer prática de ensino. 
Bio - grafia. Escritos sobre la Biología y su Enseñanza. ISSN 2027

Edición Extraordinaria. p.p. 1575-1589

Memorias del VIII Encuentro Nacional de Experiencias en Enseñanza de la Biología y la Educación Ambiental. III Congreso Nacional de Investigación en Enseñanza de la Biología.

\section{Referências}

Barbosa, R. G.; Batista, I. L. (2011). A criatividade como uma referência para discutir as bases da ciência e do seu ensino. Atas do VIII ENPEC, Campinas.

Bardin, L. (2011). Análise de conteúdo. 2. ed. São Paulo: Edições 70.

Brasil. (1996). Lei de Diretrizes e Bases da Educação Nacional n 9394, de 20 de novembro de 1996. Brasília: Diário Oficial da União.

Brasil. (2000). Parâmetros Curriculares Nacionais (Ensino Médio): bases legais. Brasília: MEC/SEF.

Campos, L. M. L; Bortoloto, T. M.; Felicio, A. K. C. (2008). A produção de jogos didáticos para $o$ ensino de ciências e biologia: uma proposta para favorecer a aprendizagem. Disponivel em: 〈http://www.unesp.br/prograd/PDFNE2002/aproducaodejogos.pdf.> Acesso em 25/jul/2012.

Damasceno, A. M. B. (2009). Um encontro da biologia com a música: por um ensino mais humanista. Dissertação de Mestrado em Ensino de Ciéncias e Matemática Pontifícia Universidade Católica de Minas Gerais, Belo Horizonte.

Fernandes, R. S.; Souza, V. J.; Pelissari, V. B. Fernandes, S. T. (2004). Uso da Percepção Ambiental como instrumento de gestão em aplicações ligadas às áreas educacional, social e ambiental. Rede CEAs. Disponivel em: <http://www.redeceas. esalq.usp.br/noticias/Percepcao_Ambiental.pdf>. Acesso em 26 fev. 2012.

Ferreira, M. (2008). Como usar a música na sala de aula. 7. ed. São Paulo: Contexto, 2008.

Granja, C. de S. E. C. (2006). Musicalizando a escola: música, conhecimento e educação. 1. ed. São Paulo: Ensaios Transversais. 
Bio - grafia. Escritos sobre la Biología y su Enseñanza. ISSN 2027

Edición Extraordinaria. p.p. 1575-1589

Memorias del VIII Encuentro Nacional de Experiencias en Enseñanza de la Biología y la Educación Ambiental. III Congreso Nacional de Investigación en Enseñanza de la Biología.

Guimarães, M. (1995). A dimensão ambiental na educação. Campinas: Papirus.

Hernández, F.; Sancho, J. M. (2000) Aprendendo com as Inovações nas Escolas. Porto Alegre: Artmed.

Jacobi, Pedro. (2003). Educação ambiental, cidadania e sustentabilidade. Cadernos de Pesquisa, 118(3), 189-205.

Leff, E. (2001). Epistemologia ambiental. São Paulo: Cortez.

Loureiro, A. M. A. (2003). O ensino de música na escola fundamental. Campinas, SP: Papirus.

Melo, T. F. T. De; Assis, M. L. G. De; Severo, T. E. A.; Silva, M. V. K. F. (2012). Ação do PIBID por meio de um projeto de Horta comunitária como estratégia didática de Educação Ambiental. Anais do XVI ENDIPE - Encontro Nacional de Didática e Práticas de Ensino: UNICAMP - Campinas: p. 6652 - 6663.

Morgado, F. da S. (2006). A horta escolar na educação ambiental e alimentar: experiência do Projeto Horta Viva nas escolas municipais de Florianópolis. Monografia de Graduação em Ciências Agrárias - Florianópolis: Universidade Federal de Santa Catarina.

Morin, E. (2003). A Cabeça Bem Feita: repensar a reforma, reformar o pensamento. 8.ed. Rio de Janeiro: Bertrand Brasil.

Muggler, C. C. Almeida, S. De; Mol, M. J. L.; Franco, P. R. C.; Monteiro, D. E. J.; (2004). Solos e Educação Ambiental: Experiência com alunos do Ensino Fundamental na Zona Rural de Viçosa, MG. Anais do $2^{\circ}$ Congresso Brasileiro de Extensão Universitária Belo horizonte: UFMG.

Ricklefs, R. E. (2010). A Economia da Natureza. 6.ed. Rio de Janeiro: Guanabara-Koogan.

Santos, P. A. M. (2005). Inovações no ensino de ciências e na educação em saúde: um estudo a partir de projeto Finlay. Dissertação de mestrado - Faculdade de Educação da 
Bio - grafia. Escritos sobre la Biología y su Enseñanza. ISSN 2027

Edición Extraordinaria. p.p. 1575-1589

Memorias del VIII Encuentro Nacional de Experiencias en Enseñanza de la Biología y la Educación Ambiental. III Congreso Nacional de Investigación en Enseñanza de la Biología.

Universidade de São Paulo, São Paulo.

Severo, T. E. A. (2012). Ecologia também é Educação Ambiental? Um estudo sobre as necessidades formativas do professor educador ambiental. Anais do XVI ENDIPE Encontro Nacional de Didática e Práticas de Ensino: UNICAMP, Campinas, 6627 6638.

Sousa, M. E; Silva, O. F; Silva, S. R. T; Silva, G. H. P. (2012). A importância das atividades lúdicas: uma proposta para o ensino de ciências. Anais do VII CONNEPI, Palmas: IFTO. 